clinically or similar in their use of resources. ${ }^{6}$ For this reason a programme to amend diagnosis related groups was initiated, and a new set of groupings (healthcare resource groups) are now available for use in resource management sites. These will be further developed over the next few years.

Until now case mix groupings in the NHS have been used only in managing resources in hospital. The internal market, however, requires a common set of treatment groups for use in contracting between purchasers and providers. These groups will have to be capable of identifying the population's health care needs and assembling them into packages that providers can offer to meet. Although final decisions have yet to be made, the logic of using one of the available case mix groupings seems compelling. For it to be workable, however, the appropriateness of the groupings will have to be acceptable to doctors. Much work needs to be done to ensure that the groups are both clinically meaningful and homogeneous in their use of resources. In addition, work is needed to extend their use beyond the acute inpatient sector.

Finally, it should be understood that the purpose of the analysis determines the method of grouping. For resource management and setting and monitoring contracts it may be right to use a grouping based on groups that consume similar resources. An isoresource grouping, however, is not necessarily useful for examining the quality and outcomes of care.
For this purpose groupings of patients with a similar prognosis or severity of disease (iso-outcome groups) are needed. Grouping case mix by diagnosis related group may be useful to identify exceptional costs and lengths of stay but is unlikely to be very useful for audit and quality assurance. For these purposes severity of illness systems, such as disease staging ${ }^{8}$ or patient management categories, ${ }^{9}$ may be more useful.

Director,

HUGH SANDERSON

National Case Mix Office,

Wessex Regional Health Authority,

Winchester,

Hampshire SO22 5DH.

Newman A, Jenkins L. Diagnosis related group experience in England 1981-1991. London: CASPE Research, 1991.

Fetter RB, Shin Y, Freeman JL, Averill RF, Thompson JD. Case mix definition by diagnosis related groups. Medical Care 1980;18(suppl 2):1-39. (management budgeting) in health authorities. DHSS, 1986. $(\mathrm{HN}(86) 34$.)

(mage $\mathrm{HF}$, Crig $\mathrm{M}$. Winth $\mathrm{CPA}$, Bevan G. Using diagn) Comon Craig $M$. Winyard

Communily Medicine $1986 ; 8: 37-47$.

Coxperiments using PACTS in Southend and Oldhom Final Report. London: CASPE Research, 1985.

6 Sanderson HF, Storey A, Morris D, McNay RA, Robson MP, Loeb J. Evaluation of diagnosis related groups in the National Health Service. Community Medicine 1989;11:269-78.

NHS Management Executive Resource Management Unit. Proposals for English casemix groups. London: NHS Management Executive, 1991

8 Gonella JS, Hornbrook MC, Louis DZ. Staging of disease. A case mix measurement. fAMA 1984:251:637-44

9 Young W. Incorporating severity of illness and comorbidity in case mix measurement. Health Care Financing Review 1984;suppl:23-31.

T)

\title{
Breast feeding in the first six months
}

\section{No need for extra fluids}

Although nearly all mothers in developing countries breast feed, few do so exclusively. ${ }^{1}$ Most supplement their milk with water or teas, frequently from the first week of life. They do so believing that such fluids will relieve pain (especially colic and earache), prevent and treat colds and constipation, soothe fretfulness, and, especially, quench thirst. Many doctors encourage them, believing that extra fluids are necessary for hydration. They shouldn't: supplementing breast milk in the first six months of life is unnecessary and may be harmful.

Exclusively breastfed infants benefit most from the protection that breastfeeding offers against diarrhoea. ${ }^{2}$ Supplementing breast milk with water or teas significantly increases the risk of diarrhoea. Studies in $\mathrm{Peru}^{3}$ and the Philippines ${ }^{4}$ found that in infants younger than 6 months supplementing breast milk with other fluids at least doubled the risk of diarrhoea. In Brazil infants who received water, tea, or juice in addition to breast milk faced a greater risk of death from diarrhoea. ${ }^{5}$ Each additional daily feed with these fluids substantially increased the risk.

Infants who receive supplementary fluids have a lower intake of breast milk than if they are exclusively breastfed ${ }^{6}$ and are also more likely to be breastfed for shorter periods. ${ }^{7}$ In Brazil infants who were offered water and teas in addition to breast milk in the first days of life were twice as likely to stop breastfeeding before the age of 3 months than infants who were exclusively breastfed. ${ }^{7}$ The use of these fluids may therefore erode the substantial benefits of breastfeeding in maintaining growth, reducing morbidity and mortality from a range of causes, and increasing birth intervals.

The average daily fluid requirement of a healthy infant depends on the concentration of the feeds, energy consumption, and environmental humidity and temperature. ${ }^{8}$ Fluid, consumption below what is required will lead to dehydration, with increases in serum and urine osmolarity. Given the low concentrations of sodium, chloride, potassium, and nitrogen in breast milk, only a relatively small amount of the fluid intake is needed for excretion of waste products. Calculations indicate that healthy infants who consume enough breast milk to satisfy their energy needs receive, with a considerable margin of safety, enough fluid to satisfy their requirements, even in hot and dry environments. ${ }^{89}$

To check the validity of these calculations six studies have measured the urine osmolarity of healthy, exclusively breastfed infants in settings with high environmental temperatures and varying degrees of humidity. ${ }^{6-13}$ Out of 572 samples that were examined, 570 had an osmolarity that was within normal limits. In only 14 samples did urine osmolarity exceed 700 $\mathrm{mmol} / 1$. In all but two samples, from children who were nevertheless considered to have an adequate water balance, ${ }^{12}$ the osmolarity was less than $1200 \mathrm{mmol} / 1$. These results support the theoretical calculations: osmolarity was maintained well within the normal concentrating ability of the kidney under extremely hot and dry conditions.

Supplementing breast milk with non-nutritive fluids undermines breastfeeding and substantially increases the risks of illness and death from diarrhoea especially among infants living in poor, unsanitary conditions. How, then, may this unsafe and unnecessary practice be discouraged? Changes in maternity services improve rates of exclusive breastfeeding in the first weeks of life. ${ }^{14}$ Ways to foster breastfeeding include informing all pregnant women how and why to breastfeed, helping mothers to initiate breastfeeding soon after birth, allowing rooming in 24 hours a day, encouraging breastfeeding on demand, and giving the infant no food or drink other than breast milk unless it is medically indicated. ${ }^{14}$ Other measures will, nevertheless, be important to ensure that exclusive breastfeeding is maintained throughout the first four to six months of life. These include protecting the rights 
of working women to breast feed and continuing to encourage and support breastfeeding through support groups and the health services. Health practitioners everywhere have an important part to play in promoting and supporting exclusive breastfeeding.

\section{JOSE C. MARTINES Međical Officer MARINALREA Medical Officer \\ ISABELLE DELZOYSA Research Coordinator}

Diarrhoeal Disease Control Programme,

World Health Organisation,

1211 (Geneva zz, Switzerland)

1 United States Agency for International Development. Breastfeeding: a report on AID program Washington, DC: US Agency for International Development, 1990.

2 De Zoysa I, Rea M, Martines J. Why promote breastfeeding in diarrhoeal disease control programmes? Health Policy and Planning 1991;6:371-9.
3 Brown KH, Stallings RY, Creed de Kanashiro H, Lopez de Romana G, Black RE. Effects of common illnesses on infants' energy intakes from breast milk and other foods during longitudinal
community-based studies in Huascar (Lima), Peru. Am f Clin Nutr 1990;52:1005-13. community-based studies in Huascar (Lima), Peru. Am f Clin Nutr 1990;52:1005-13. Popkin BM, Adair L, Akin JS, Black R, Briscoe J, Flieger W. Breast-feeding and diarrhea morbidity. Pediatrics 1990;86:874-82.

5 Victora CG, Smith PG, Vaughan JP, Nobre LC, Lombardi C, Teixeira AMB, et al. Infant feeding and deaths due to diarrhea: a case-control study. Am F Epidemiol 1989;129:1032-41.

6 Sachdev HPS, Krishna J, Puri RK, Satyanarayana L, Kumar S. Water supplementation in exclusively breastfed infants during summer in the tropics. Lancet 1991;337:929-33.

7 Martines JC, Ashworth A, Kirkwood, B. Breast-feeding among the urban poor in southern Brazil: reasons for termination in the first 6 months of life. Bull World Health Organ 1989;67:151-61. Akre J, ed. Infant feeding: the physiological basis. Bull World Health Organ 1989;67(suppl):1-108. 9 Almroth SG. Water requirements of breastfed infants in a hot climate. Am $\mathcal{J}$ Clin Nur 1978;31:1154-7.

10 Armelini PA, Gonzalez CF. Breastfeeding and fluid intake in a hot climate. Clin Pediatr 1979;18:424-5.

11 Goldberg NM, Adams E. Supplementary water for breast-fed babies in a hot and dry climate-not really a necessity. Arch Dis Child 1983;58:73-4.

12 Almroth S, Bidinger PD. No need for water supplementation for exclusively breast-fed infants under hot and arid conditions. Trans $R$ Soc Trop Med Hyg 1990;84:602-4.

13 Brown KH, Creed de Kanashiro H, del Aguila R, Lopez de Romana, G, Black RE. Milk consumption and hydration status of exclusively breast-fed infants in a warm climate. $\mathcal{f}$ Pediat 1986;108:677-8.

14 Canahuati J. One country's story: the PROALMA program in Honduras. In $\mathcal{f}$ Gynecol Obste 1990;31(suppl 1):17-24.

15 World Health Organisation, United Nations Children's Fund. Protecting, promoting and supporting breast-feeding: the special role of maternity services. Geneva: WHO, 1989.

\title{
Advances in the treatment of chronic heart failure
}

\author{
Two steps forward, one step back
}

Three trials have recently been published with important implications for the treatment of heart failure. They answered two questions. The first was whether enalapril, an angiotensin converting enzyme inhibitor, would improve mortality when added to conventional treatment in patients with mild or moderate heart failure; the cooperative north Scandinavian enalapril survival study CONSENSUS had already shown that angiotensin converting enzyme inhibitors increased survival in patients with severe heart failure. ${ }^{1}$ The second was whether a positive inotropic drug such as milrinone, a phosphodiesterase inhibitor, would improve mortality in patients with heart failure who were still symptomatic despite maximum conventional treatment including diuretics and an angiotensin converting enzyme inhibitor.

The studies of left ventricular dysfunction (SOLVD) were designed in two parts. ${ }^{2}$ The treatment arm included patients with heart failure who were being treated with drugs other than angiotensin converting enzyme inhibitors (usually diuretics) and had a left ventricular ejection fraction of less than $35 \% .^{3}$ Most of the cases of heart failure were due to coronary heart disease. Two thirds of the patients had no or only slight limitation of physical activity (New York Heart Association functional class I or II disease), and four out of five were male. In the prevention arm patients had a left ventricular ejection fraction of less than $35 \%$ but were asymptomatic (or nearly so) and not receiving any treatment for heart failure. The treatment arm randomised 2569 patients to either placebo or enalapril starting at a dose of 2.5 $\mathrm{mg}$ a day and increasing to a maximum of $10 \mathrm{mg}$ twice a day. ${ }^{3}$ After a mean follow up of $3^{1 / 2}$ years there were significantly more deaths in the patients treated with placebo than with enalapril (510/1284 $v$ 452/1285). This difference may have been an underestimate: nearly a quarter of the patients in the placebo group were taking angiotensin converting enzyme inhibitors after three years.

Significantly fewer patients were admitted to hospital for worsening heart failure. The benefits occurred in all subgroups regardless of plasma sodium concentration, treatment with other vasodilators, or cause or severity of heart failure. There was a suggestion that patients with no limitation of physical activity or with an ejection fraction of $30-35 \%$ may have benefited less than those with worse heart failure.
At a meeting of the American Heart Association last November the unpublished results of the prevention arm of the studies were presented. In this study 4228 patients were randomised to placebo or enalapril. Although differences in total mortality and cardiovascular mortality were not significant, the rate of admission to hospital, the frequency of progression to overt heart failure, and the incidence of myocardial infarction were lower in the patients treated with enalapril. Patients with higher ejection fractions benefited less.

The second Veterans Administration cooperative vasodilator heart failure trial (V-HeFT II) compared the effect of combined isosorbide dinitrate and hydralazine with that of enalapril ( $5 \mathrm{mg}$ initially, increasing to $20 \mathrm{mg}$ daily) in $804 \mathrm{men}$ with a mean age of $61 .^{4}$ The criteria for inclusion were cardiac dysfunction and reduced exercise tolerance despite optimal treatment with diuretics and digoxin. Half the patients had slight symptoms (New York Heart Association functional class II). The mean oxygen consumption was $14 \mathrm{ml} / \mathrm{kg} / \mathrm{min}$ and $30 \%$ drank alcohol. Mortality at two years was $25 \%$ in patients treated with isosorbide dinitrate and hydralazine, significantly higher than the mortality of $18 \%$ in patients treated with enalapril. The first Veterans Administration heart failure trial (V-HeFT I) had previously shown that the combination of nitrates and hydralazine reduced mortality compared with placebo. ${ }^{5}$ An identical outcome of both Veterans Administration trials with the same entry criteria and this combination of drugs allowed a comparison of the placebo group from the first trial and the enalapril group from the second trial. Mortality at two years was $34 \%$ in patients treated with placebo compared with $18 \%$ in patients treated with enalapril.

The patients admitted to the second Veterans Administration trial probably had more severe heart failure than those in the studies of left ventricular dysfunction. The average age of patients in both trials was below that of patients with heart failure in a population study, ${ }^{6}$ suggesting some selection of patients had occurred, possibly related to attendance at hospital. Surprisingly, neither study stated the dose of diuretics received by patients. In the second Veterans Administration trial mortality from sudden death was reduced, whereas in the studies of left ventricular dysfunction and the 